\title{
O QUE MARX NOS PODE ENSINAR SOBRE \\ A NOVA "CLASSE PERIGOSA" - CRÍTICA, NEOLIBERALISMO E O FUTURO DA EMANCIPAÇÃO HUMANA
}

\author{
MARTA NUNES DA COSTA
}

\section{RESUMO}

Marx via no proletariado a classe revolucionária. Hoje, autores como Guy Standing defendem que o proletariado, enquanto "classe" específica, está a dar lugar à nova (não) classe do precariado. Se o projeto marxista de uma revolução do proletariado não aconteceu ainda, queremos perguntar: pode o precariado ser o novo agente de mudança, num contexto em que o sistema capitalista ganhou contornos neoliberais? Neste artigo queremos tentar responder a essa questão, explorando o diálogo entre Marx e Hegel, por um lado, e o precariado e o fenómeno neoliberal, por outro.

PALAVRAS-CHAVE: Marx, Hegel, proletariado, precariado, neoliberalismo, emancipação.

\section{ABSTRACT}

Marx saw the proletariat as the revolutionary class. Today, authors like Guy Standing argue that the proletariat, as a specific "class", is giving place to the new (non) class of the precariat. Given that the Marxist project of a revolution led by the proletariat is still to happen, can the precariat be(come) the new agent of change, in a context marked by a neoliberal turn within the capitalist system? In this paper we will try to answer this question: on the one hand, by exploring the dialogue between Marx and Hegel, on the other hand, by exploring the relationship between the precariat and the neoliberal phenomenon.

KEYWORDS: Marx, Hegel, proletariat, precariat, neoliberalism, emancipation.

Milhares de páginas têm sido escritas acerca de Marx e das variantes marxistas (fiéis ou infiéis a Marx). É compreensível essa dedicação ao autor, que traz consigo o reconhecimento da pertinência do seu pensamento para os diferentes momentos de contemporaneidade. Se Marx era um autor verdadeiramente contemporâneo no tempo em que escreveu, na medida em que se debruçou sobre a especificidade do seu contexto social, político e histórico, é verdade também que Marx permanece contemporâneo desde então, até aos dias de hoje. Independentemente do que nos possa afastar ou aproximar de Marx, 
concordemos ou não com várias leituras que ele nos propõe, o certo é que, tal como Peter Singer diz, "somos todos marxistas agora" (Singer, 2000, p.3).

A obra de Marx é marcada por reflexões críticas sobre a sua época. Desde os primeiros textos até seus textos maduros, a crítica é um elemento vincadamente presente, desdobrado nas suas múltiplas funções de descrição, juízo e proposta. A crítica apareceu como imperativo, num momento em que se assistia a uma reconfiguração social e política drástica: a emergência e a consolidação de novas classes sociais, aliadas à defesa e à proliferação de um novo modelo de produção, criavam as condições perfeitas para que as lutas (de classes) que haviam permanecido até então à margem da esfera pública ganhassem visibilidade e existência política. Essa visibilidade - do proletariado, como classe universal - enquanto conquista política só foi possível porque autores como Marx descreveram criticamente uma realidade que se estava a consolidar e que ainda estava no processo de formação da sua própria consciência. Parece-nos, por isso, crucial retomar Marx para pensar as condições em que vivemos hoje.

Marx via no proletariado a classe revolucionária. Hoje, autores como Guy Standing defendem a tese de que o proletariado, enquanto "classe" específica, realidade concreta e relativamente estável (mesmo que na sua condição de luta), está a dar lugar a outro fenômeno: o precariado, e essa é a "nova classe perigosa". O precariado partilha várias características com o proletariado - o seu caráter universal, a sua dimensão de negação, entre outras -, mas não se reduz, nem se limita, a ele. Se o projeto marxista de uma revolução do proletariado não aconteceu ainda - ou aconteceu de forma deturpada e interrompida -, queremos perguntar: pode o precariado ser o novo agente de mudança, capaz de superar o modo de produção capitalista - tal como tem sido perpetuado até hoje, culminando no abraço forçado do imperialismo neoliberal? Ou seja, independentemente de subscrevermos ou não uma política "dita" de esquerda, temos vários dados que nos levam a crer que estamos diante de uma reconfiguração de forças geopolíticas, econômicas e financeiras, que simplesmente sufocam e esmagam qualquer ideal emancipador da vida humana. A tendência de acumulação do capital levada ao extremo tem gerado aquilo que Marx havia já denunciado nos Manuscritos econômico-filosóficos de 1844 a alienação do ser humano. Por isso, será altura de perguntar, a emancipação humana é ainda possível? E em que termos? Sob que condições?

Neste artigo queremos tentar responder a essa questão, explorando o diálogo entre Marx e Hegel, por um lado, e o novo precariado e o fenômeno neoliberal, por outro. Assim, o artigo tem quatro momentos. No primeiro momento, começamos por explorar o diálogo entre Marx e Hegel partindo da análise do papel desempenhado pela dialé- 
tica e pela filosofia. No segundo momento, olhamos para a os sentidos de alienação em Marx, sobretudo com referência aos Manuscritos econômico-filosóficos de 1844, tendo em consideração a leitura avançada por Hegel nos Elementos da filosofia do direito. O terceiro momento descreve as características do proletariado como classe revolucionária. Por fim, o quarto momento consiste numa descrição da nova (não) classe do precariado, à luz da interpretação crítica do fenômeno do neoliberalismo. Pretendemos oferecer bases para uma reflexão crítica acerca da possibilidade (ou necessidade) de emancipação humana, sobre o que podemos fazer, e o que podemos esperar.

\section{MARX EM DIÁLOGO COM HEGEL - DIALÉTICA E FILOSOFIA}

O conceito de alienação é recorrente nos escritos de Marx, e carrega consigo significados teóricos, práticos e simbólicos específicos. Com efeito,é impossível falar de Marx sem falar do papel determinante que a alienação desempenha no seu pensamento e em sua proposta prática. Porém, o entendimento que geralmente passa desse conceito para o público acadêmico e o público em geral nem sempre é fiel à forma como o próprio Marx o utilizava, e ignora, muitas vezes, o contexto de sua emergência e utilização e sua relação com outros autores, nomeadamente Hegel.

Convém esclarecer desde já que para Marx o conceito de alienação tem um significado bastante preciso e objetivo. Não é um conceito de nos remeta a uma ordem moral ou de qualquer tipo de transcendência; é, pelo contrário, um conceito que se identifica no contexto específico econômico, e que fala com uma tradição filosófica que havia já reconfigurado a relação entre história e filosofia, e o papel do ser humano no desenrolar dessa relação. Se queremos, por isso, compreender o papel do conceito de alienação em Marx, temos de recuar e perceber a quem - e a quê - está Marx a responder.

Hegel é um autor difícil em muitos aspectos, porém, quando mergulhamos na sua obra, percebemos a riqueza do seu pensamento e a revolução que este traz consigo, afetando toda a história da filosofia e como pensamos - e fazemos - filosofia até hoje.

Hegel deparava com o dilema clássico entre determinismo e liberdade. Como conciliar o determinismo das leis naturais com a liberdade do mundo numênico? Estaríamos condenados ao abismo inultrapassável entre mundos, tal como Kant anunciara? Hegel responde a essa questão reconfigurando as premissas do trabalho kantiano e introduzindo um novo método, que permitiria fazê-lo. Se era evidente para Hegel que o sujeito só se afirma como ser autônomo e racional no processo de separação consciente do domínio da natureza, é também evidente que o desenvolvimento da consciência só é pos- 
sível a partir do reconhecimento de que as dicotomias (abismos ou antinomias) encerram em si os seus momentos anteriores. Isto em si mesmo é revolucionário, ou seja, admitir que o dualismo, a tensão, o conflito, a luta, a antinomia têm, em si mesmos, na sua base, a fonte de resolução e superação. Não podemos pensar as relações de oposição e de identidade separadas uma da outra. Por isso, Hegel chega a uma proposta lógica que vai regular a edificação do seu sistema, em que $\mathrm{A}=\mathrm{A}, \mathrm{A}=\mathrm{nA}$ e, num terceiro momento, só depois é possível $\mathrm{A}=\mathrm{A}$. $\mathrm{A}$ identidade tem, no seu interior, a sua própria alteridade, o seu momento de alienação, o estar fora de si, mas esse "estar fora" é essencial (e não acidental), e permite retornar a si - não eliminando as diferenças, mas preservando-as e chegando a uma unidade mais rica e complexa.É este o sentido de "Aufheben".

A constatação - e invenção - dessa proposta permitiu a Hegel repensar as grandes dicotomias que marcaram a filosofia. Desde o dualismo cartesiano até o dualismo kantiano, Hegel percebeu que, se a identidade tem em si mesma o conflito que deve ser superado para ser idêntica a si mesma, então isso quer dizer que a liberdade não pode ser redutível ao pensamento apenas - deve passar pela matéria; ou, por outro ângulo, a matéria contém em si as sementes da própria racionalidade que permite que a liberdade se atualize e se traduza no mundo. Assim, o próprio conceito de racionalidade passa por uma transformação, já que não deve ser tido como ponto de partida "puro e absoluto", mas antes como resultado de um processo que se desenvolve no tempo e no espaço. Hegel rompe assim com a tradição na qual está inserido, afirmando a importância fundamental da temporalidade e da própria historicidade'.

Essa ruptura faz-se através da introdução de um novo método e conceptualização de racionalidade, a saber, a dialética: enquanto Kant defendia a tese de que a razão, ao tentar ultrapassar os limites da experiência possível e conhecer o que está para lá dela, cai em antinomias, e por isso tem de limitar-se ao domínio da natureza, Hegel parte da constatação de que o ser humano tem a tendência incontrolável de querer ultrapassar os seus limites. Ele associa isso à ideia de o ser humano estar aberto e virado para a mudança, para o desenvolvimento, para o progresso, passando de um estado de conflito para um estado de resolução. É claro que para o entendimento (kantiano) a dialética seria uma aberração e causa de paradoxo. Mas Hegel insiste que o pensamento é dinâmico, que se transcende e se supera a si mesmo. $\mathrm{O}$ pensamento não pode ser confinado a um território específico e os paradoxos dialéticos não podem ser evitados, nem reduzidos a ilusões. Assim, para Hegel a solução não reside em evitar o conflito, mas em sistematizar os paradoxos. Se o pensamento dá origem a contradições, ele próprio irá levar à reconciliação numa unidade superior ${ }^{2}$.
[1] Taylor, Charles. Hegel. Cambridge: Cambridge University Press, 1999.

\footnotetext{
[2] Hegel consegue fazer isso por causa da sua teoria da realidade: a realidade é constituída pelo nosso pensamento acerca dela; e o pensamento implica aspectos ou momentos contraditórios: logo, a realidade tem de incarnar essas mesmas contradições. O pensamento contraditório é tolerável se formos capazes de distinguir claramente os seus aspectos contraditórios e reconciliá-los numa concepção teórica mais elevada. Ver Wood, Allen W. Hegel's ethical thought. Cambridge: Cambridge University Press, 1990, pp.1-2.
} 
[3] Marx, Karl. Para a crítica da filosofia do direito de Hegel. Covilhã: Textos Clássicos, LusoSofia, 2008, p. 13.
[4] Hegel, G.H.F., Elements of the philosophy of right, tradução de H.B. Nisbet, Cambridge: Cambridge University Press, 2003, p. 21, itálico adicionado.
Assim, o sujeito racional de Hegel é um sujeito que está encarnado na matéria, no corpo, na história, na cultura, na nação. O corpo aparece como oposto vital à realização da própria liberdade e a alienação é parte integrante de todo e qualquer processo racional. Seja no âmbito da religião, da cultura, da nação ou do próprio indivíduo, a alienação está sempre presente como momento contraditório que contém os elementos que conduzem à sua própria superação.

Marx, embora reconhecesse a radicalidade da proposta de Hegel, sobretudo pela introdução da dialética como método e princípio regulador do inquérito filosófico e da própria crítica, considerava que a crítica que Hegel havia feito do seu tempo era apenas parcial. Como ele diz na Crítica à filosofia do direito de Hegel,

A crítica da filosofia alemã do direito e do Estado, que teve a mais lógica, profunda e completa expressão em Hegel, surge ao mesmo tempo como a análise crítica do Estado moderno e da realidade a ele associada e como a negação definitiva de todas as anteriores formas de consciência na jurisprudência e na política alemã, cuja expressão mais distinta e mais geral, elevada a ciência, é precisamente a filosofia especulativa do direito. [...] o representante alemão do Estado moderno [...] que não toma em linha de conta o homem real, só foi possível porque e na medida em que o próprio Estado moderno abstrai do homem real ou unicamente satisfazo homem total de maneira ilusória 3 .

Tendo em conta o que dissemos anteriormente, podemos questionar se a crítica que Marx faz a Hegel é justa ou injusta. Estamos tentados a considerá-la justa, se for apenas de forma parcial, à custa da não consideração da totalidade orgânica do seu próprio pensamento. Marx diz, numa famosa passagem das Teses de Feuerbach que "os filósofos interpretaram apenas o mundo, de várias formas; o objetivo, porém, é mudá-lo". A crítica é parcialmente justa na medida em que, embora ambos os autores pretendam responder à mesma questão como compreender a condição do presente -, adotam posturas e perspectivas diferentes. Hegel, na introdução dos Elementos da filosofia do direito, diz que a tarefa da filosofia é compreender o presente e o atual, perceber a dinâmica real e concreta do Espírito na dimensão temporal e transitória; ou seja, Hegel não nos quer oferecer uma proposta de como deve ser o mundo, mas antes captar a dinâmica e o movimento do mundo que é. É nesse sentido que o autor diz que "Compreendero que é,é a tarefa da filosofia, pois o que é é razão. No que diz respeito ao indivíduo, cada individuo éfilho do seu tempo, logo, a filosofia tambémé oseu próprio tempo compreendido em pensamentos. É tolice pensar que qualquer filosofia possa transcender o seu mundo contemporâneo [...]"4.

O reconhecimento do que mais tarde seria definido por Foucault 
como "a priori histórico", ou seja, de que só podemos pensar a nossa condição presente com os instrumentos, conceitos e ideias definidos dentro da especificidade temporal e histórica, permite-nos também afirmar que Hegel fez exatamente o que podia ter feito, e que a crítica de Marx à abstração do sistema hegeliano só pode encontrar justiça se ignorarmos o fato de que Hegel pensava a sua condição, e não o futuro, mesmo que futuro próximo. O que talvez separe mais os autores é a postura que têm em relação à tarefa da filosofia. Para Hegel, a filosofia, enquanto pensamento do mundo, chega sempre tarde para realizar a sua tarefa; a filosofia não pode nunca pretender transformar o mundo, porque ela é o reflexo de cada momento histórico que está em vias de terminar, e por isso pode ser pensado. Para Marx, claro, as ideias têm um papel fundamental e transformador da ordem das coisas; logo, a filosofia não deve apenas compreender o queé, mas sim transformaro que é de acordo com o que deve ser. Por outras palavras, não basta descrever ou estar consciente da alienação do mundo, é preciso procurar a raiz dessa alienação e extirpá-la, para que o ser humano se emancipe.

Fica claro que sem a interpretação que Hegel faz do mundo Marx não seria Marx, pois só graças a Hegel pode Marx levar a dialética mais longe, e inquirir sobre as condições de alienação contemporânea.

Por isso, se voltarmos à passagem de Marx acusando Hegel de dissociar o homem real do homem abstrato, vemos que, propondo uma nova perspectiva - a partir do real e não do ideal ou pensamento -, Marx pretende com a crítica revelar a raiz das coisas, e mostrar que "para o homem, a raiz é o próprio homem"s.

\section{SENTIDOS DE ALIENAÇÃo}

Marx, no decorrer da sua obra, vai definir o seu pensamento em contraposição a três interlocutores: a filosofia de Hegel, a economia política "clássica" e o socialismo utópico. É através desse diálogo crítico que Marx chega à unicidade da sua proposta filosófica e política. De Hegel, Marx recupera e leva às suas últimas consequências o método dialético. Apesar das diferenças radicais que possam separar os dois autores, ambos partilham algo de essencial, a saber, ambos querem compreender a fragmentação da vida moderna, entendida no seu duplo aspecto de totalidade social e parte individual.É exatamente nessa tentativa de compreensão que ambos encontram nos conceitos de trabalho e de alienação a fonte para o sentido da sua condição presente.

O conceito de trabalho em Hegel é importante não só porque aponta para os meios que o Espírito tem de se realizar e se objetivar no mundo, mas também porque, subjacente a ele, está a constatação da impossibilidade de separação entre teoria e prática, pensamento e ação. Ou seja, o trabalho é a ação pela qual o sujeito transforma o
[5] Marx começa exatamente com a crítica, como método e disciplina capaz de abarcar a totalidade do seu objeto, capaz de chegar à raiz, capaz de superar as suas próprias limitações enquanto atividade teórica $e$ transcender-se ao converter-se em força material, "capaz de se apossar das massas ao demonstrar-se ad hominem, e demonstra-se ad hominem logo que se torna radical" (Marx, 2008, p. 14). 
[6] Marx, Karl. In: Tucker (org.), The Marx-Engels reader. Nova York:W.W. Norton \& Company, 1978, p. 150

[7] Aquelas contradições que definem e constituem a sociedade civil hegeliana, mas que em última instância encontram resolução no Estado (embora se levante o problema estrutural da pobreza, que Hegel nunca resolve), são tomadas por Marx como indicadores de algo que marca e redefine a condição humana afastando-a da sua essência. Por isso, para perceber como superar essas contradições é preciso compreender o que está na raiz da alienação do homem. Só depois de identificar a causa será possível considerar estratégias para a emancipação humana. mundo; é a apropriação que o sujeito faz do mundo; é a forma pela qual o sujeito se objetiva e também se conhece nesse objeto, dando uma forma humana ao mundo natural. É também o meio pelo qual a autoconsciência individual e coletiva se desenvolve, através dessa objetivação de si no mundo. Assim, o trabalho é uma atividade essencial que distingue os seres humanos dos outros animais. Pelo trabalho o homem desenvolve-se como autoconsciente pela intenção que traduz pela sua ação sobre o mundo.

A economia política, por sua vez, toma também o conceito do trabalho como sua categoria central, porém vai ignorar o caráter essencialmente humano (i.e., social) que quer Marx quer Hegel lhe reconhecem. No § 189 dos Elementos da filosofia do direito, Hegel diz que "a economia política é a ciência que deve explicar as relações de massa e os movimentos de massa na sua determinação e complexidade qualitativa e quantitativa". Ou seja, Hegel reconhece que a economia política é uma disciplina especificamente moderna, que visa compreender a nova configuração do Estado moderno. Para a economia política (Adam Smith, Ricardo, Say etc.) o trabalho é visto como atividade meramente instrumental, ou seja, como meio para atingir os fins, i.e., a satisfação das necessidades específicas (de sobrevivência). Subjacente a essa concepção de trabalho está a postulação de uma "mão invisível" (Adam Smith) que guia o universal a partir das ações dos cidadãos privados. Num certo sentido, essa "mão invisível" torna-se perfeitamente compatível com o sistema hegeliano em que o trabalho do Espírito consegue garantir sentido e superar as contradições imanentes da sociedade civil.Adialética permite pensar que, independentemente da consciência que os agentes individuais tenham do processo do qual fazem parte, as suas ações irão, em última análise, contribuir para a satisfação das necessidades de todos.

Ora, é exatamente essa concepção da economia política (que Marx vai designar como "clássica", referindo-se a esses autores), baseada numa leitura específica de acumulação primitiva, trabalho e razão que governa o mundo, que Marx vai criticar. Para Marx o trabalho é a marca especificamente humana do ser humano. $\mathrm{O}$ homem só existe enquanto homem trabalhando, agindo, transformando o mundo, expressando a sua individualidade através dessa ação. Ou seja, o homem é o agente da história que se distingue dos outros animais a partir do momento em que começa a produzir a sua vida material atual ${ }^{6}$.

O estabelecimento do modo de produção capitalista vem colocaro homem em oposição à sua própria essência, já que rouba a este todas as condições para um trabalho e uma produção autónomos7. Nos $M a$ nuscritos econômico-filosóficos de 1844 encontramos a primeira grande interpretação de Marx acerca do fenômeno da alienação econômica (que Marx considera a raiz de todas as alienações, inclusive a religiosa). 
Partindo das premissas da economia política, a saber, da propriedade privada, competição, divisão de trabalho e mais-valias, Marx vai mostrar como essas categorias encerram em si contradições que mantêm o homem numa condição de alienação. É preciso começar com uma crítica à economia política para mostrar que "a economia estabelece uma forma de relação social como forma essencial, original e natural"8, mas que essa relação tem de ser analisada, criticada e exposta. Assim, Marx parte do fato atual econômico queé o fato de que

O trabalhador torna-se mais pobre quanto mais riqueza produz, mais a sua produção aumenta em poder e âmbito. O trabalhador torna-se uma comodidade mais barata do que as comodidades que ele cria. Com o crescente valor do mundo das coisas está em proporção direta à desvalorização do mundo dos homens. O trabalho produz não apenas comodidades, mas também o trabalhador como comodidade [...]?.

[9] Marx, 1978, p. 71.

Não sendo ele mesmo um economista, Marx quer porém levantar as grandes questões que os economistas ignoravam, nomeadamente, qual o sentido da redução de grande parte da humanidade a trabalho abstrato? Ou seja, como explicar esse fenômeno de redução do trabalho como atividade livre e criadora a um trabalho em que o próprio trabalhador se reduz a mercadoria e se torna indistinguível de todos os outros que realizem a mesma tarefa?

Nesse texto Marx oferece-nos a descrição das várias dimensões de alienação humana, explícitas na conversão do trabalho criador em trabalho abstrato. Para começar, Marx mostra como o objeto produzido pelo trabalho aparece como poder independente e como estranho ao trabalhador que o produz. Esse é o primeiro sentido de alienação, o sentido em que o trabalhador se torna escravo do seu objeto. A economia política esconde esse estranhamento, porque ignora a relação direta entre o trabalhador e o processo produtivo. O sujeito não está só alienado do objeto que produz, como também da atividade e do processo de produção, na medida em que o trabalho se lhe apresenta como algo externo, como algo que não pertence à sua essência, como atividade que nada tem de espontânea. Esse é o segundo sentido de alienação, que é uma característica específica das nossas condições sócio-históricas. O trabalho torna-se uma obrigação, reduz-se a um meio para satisfazer necessidades externas ao próprio processo; logo, perde o seu caráter de expressão da autonomia e individualidade criativa ecriadora. Como consequência, o homem só se sentelivre nas suas funções animais, e por isso "o queé animal torna-se humano, e o queé humano torna-se animal"10. A partir do momento em que os homens deixam de ter controle sobre o que produzem, estão alienados da sua humanidade essencial - esse é o terceiro sentido de alienação, que

[10] Marx, 1978, p. 75 . 
[11] Marx, 1978, p. 95.

[12] Marx, 1978, p. 96.

[13] Marx, 1978, p. 100. diz respeito à alienação do homem do seu próprio potencial humano. Nessa relação de produção, o trabalho estranho torna a dimensão universal do homem - a sua capacidade criadora, livre, consciente num mero meio para a existência e sobrevivência física. Isso conduz ao quarto sentido de alienação, ou estranhamento que o homem tem em face dos outros homens. Marx, tal como Hegel, vê o ser humano como ser social e o trabalho como atividade especificamente humana. A implicação de o homem alienar-se do objeto que produz, da atividade produtora e da sua essência criadora leva a que ele se aliene igualmente dos outros seres humanos. Ou seja, chegamos a uma constelação socioeconômica em que os seres humanos são átomos isolados uns dos outros.

A conceptualização da economia política clássica é problemática para Marx porque toma as condições de alienação como ponto de partida, como "fatos" universais, como "dados" reais, generalizáveis. Por estar convencida de que a alienação é a condição natural do homem, segue-se que este possa ser reduzido a um "ser insensível privado de todas as necessidades" ${ }^{11}$; por isso também Marx considera a economia política como a ciência da negação da vida, em que "quanto menos és, mais tens, quanto menos expressas a sua vida, maior é a tua vida alienada"12. Do ser passamos ao ter; a humanidade e a vida são substituídas por dinheiro e riqueza. Esse estranhamento "é manifesto não apenas no facto de que os meus meios de vida pertencem a outrem, que o meu desejo é uma posse inacessível de outro, mas também no facto de que tudo é em si mesmo diferente para si - que a minha atividade é outra coisa, e que, por fim (o que se aplica também ao capitalista), tudo está sob o domínio do poder desumano"13.

A descrição crítica da condição alienada do ser humano supõe, porém, uma normatividade derivada do próprio método dialético. Mesmo apresentando-nos esse retrato de perda de humanidade dos seres humanos, supõe-se que nessas condições seja possível encontrar a fonte da sua superação. Daí que em Marx, tal como em Hegel, o conceito de alienação tenha de ser compreendido como fenômeno simultaneamente negativo e positivo. Ou seja, a a lienação traz consigo sempre sofrimento, luta, conflito, mas aponta também para a possibilidade da sua resolução; a alienação é condição necessária para o desenvolvimento da autoconsciência - do individuo e da espécie - no desenrolar da história. Aesperança dessa resolução é encontrada no proletariado.

\section{O PROLETARIAdO E A TAREFA REVOLUCIONÁRIA}

Se a alienação, da forma como hoje a entendemos, é um produto e reflexo do modo de produção capitalista, então como superar esse estado ou essa condição? 
N'A sagrada família, Marx dá-nos uma boa descrição da dinâmica entre capitalistas e proletariado. Ambos "representam uma e a mesma autoalienação humana"14, na medida em que os primeiros definem a sua existência pela propriedade privada, e sendo esta expressão de alienação, é vista por eles como sinal do seu poder; enquanto os segundos "se sentem destruídos nesta alienação, vendo-se na sua própria impotência e a realidade da sua existência desumana". ${ }^{15}$ Umé indissociável do outro; o que um tem de conservador, o outro tem de destrutivo; no movimento dialético vivem em mútua dependência, em permanente tensão e conflito. A natureza dialética do movimento econômico, traduzido nas relações de trabalho e na divisão social de trabalho, segue uma lógica que inicialmente pode parecer imperceptível, inconsciente; esse movimento econômico, específico e próprio do modo de produção capitalista, que visa acumular capital à custa da exploração humana, gera, a partir de si mesmo, tal pobreza que esta se torna consciente de si mesma. Ou seja, a pobreza que Hegel antecipou como endêmica ao sistema, sem conseguir porém encontrar uma resolução para ela, a não ser através da colonização ou da expansão de mercados internacionais, é a pobreza que Marx toma como elemento capaz de superar o próprio sistema capitalista. Uma pobreza que tem consciência da sua pobreza, da sua alienação, da sua desumanização. Por isso o proletariado adquire um papel histórico mundia ${ }^{16}$ : só uma classe que representa toda a negatividade da (não) existência humana é capaz de encontrar em si mesma a força para destruir as condições da sua (não) existência. Por outras palavras, só quemjá não existe enquanto ser humano, quem se reduz a mero átomo disperso na multidão anônima, mas que tem porém consciência dessa perda eé forçado "à indignação contra essa desumanidade", é capaz de lutar pela recuperação da sua humanidade. Marx diz claramente que

só em nome dos interesses gerais da sociedade é que uma classe particular pode reivindicar a supremacia geral. Para alcançar esta posição libertadora e a direção política de todas as esferas da sociedade, não bastam a energia e a consciência revolucionárias. Para que a revolução de um povo e a emancipação de uma classe particular da sociedade civil coincidam, para que uma classe represente o todo da sociedade, outra classe tem de concentrar em si todos os males da sociedade, uma classe particular deve encarnare representar um obstáculo e uma limitação geral. Uma esfera social particular terá de surgir como o crime notório de toda a sociedade, a fim de que a emancipação de semelhante esfera surja como uma emancipação geral ${ }^{17}$.

[17] Marx, 2008, p.18

\section{E ele continua dizendo que}

na formação de uma classe que tenha cadeias radicais, de uma classe na sociedade civil que não seja uma classe da sociedade civil, de uma classe que 
[18] Marx, 2008, p. 20.

[19] Marcuse, Herbert. Reason and revolution - Hegel and the rise of social theory. Boston: Beacon Press, 1978, p. 291.

[20] Marx, Karl.Manifesto comunista. Tradução Álvaro Pina. São Paulo: Boitempo Editorial, 2005, p. 40, nota.

[21] Marcuse, 1978, p. 292. seja a dissolução de todas as classes, de uma esfera que possua caráter universal porque os seus sofrimentos são universais, e que não exige uma reparação particular porque o mal que lhe é feito não é um mal particular, mas o mal emgeral $[. . .]^{18}$.

O proletariado é uma classe universal porque encarna a alienação profunda do homem; o proletariado manifesta a contradição da geração de riqueza e mais-valias com o crescimento de uma pobreza não "naturalmente existente", mas sim "artificialmente produzida". Essa pobreza "artificialmente produzida" é resultado direto da divisão social de trabalho que desconsidera a natureza social do homem e ignora os talentos, interesses ou vocações individuais. A existência do proletariado é a prova de que, ao contrário do que Hegel havia pensado, a verdade ainda não se realizou na história, e permanecemos na condição de alienação a superar.

Mas quem faz parte do proletariado, ou, por outras palavras, o que constitui o proletariado enquanto classe específica?

Como Marcuse nos alerta, as duas classes fundamentais - do proletariado e da burguesia - "não são classes no mesmo sentido"19. A burguesia é descrita no Manifesto comunista como detentora "dos meios de produção social e empregadores de trabalho assalariado" e o proletariado, por sua vez, é "a classe dos trabalhadores assalariados modernos que, não tendo meios de produção próprios, estão reduzidos a vender a sua força de trabalho de forma a viver" ${ }^{20}$. Ou seja, o proletariado significa não uma classe no sentido positivo, mas sim a negação de todas as classes. A sua luta não é para defender algum interesse específico, mas sim o interesse universal da sociedade como um todo. "O proletariado é a negação não só de certas potencialidades humanas particulares, mas também do homem enquanto tal" ${ }^{21}$. Ou seja, o proletariado é a (não) classe cuja existência se resume ao processo de trabalho. Nessa (não) classe encontramos os trabalhadores assalariados, mas estes não se limitam aos trabalhadores fabris ou das indústrias. Aparentemente, somos levados a crer que, para que o proletariado mantenha a sua dimensão universal, então teria de incluir a maioria das pessoas da sociedade capitalista, e isso significa incluir os trabalhadores rurais. Mas onde colocar, por exemplo, a intelligentsia, os médicos, jornalistas, filósofos, professores etc.? São parte do proletariado ou fazem parte da burguesia? Marx parece crer que a intelligentsia está do lado da burguesia, na medida em que corresponde ao trabalho mental (versus trabalho físico) que se enquadra na divisão de trabalho interna a essa classe. $\mathrm{Na}$ Ideologia alemã o argumento vai nesse sentido (embora Marx nunca coloque a hipótese de que a sua descrição e proposta possa ser tida como "ideologia"). Mesmo que essa seja uma discussão que dificilmente gere consenso acerca da divisão de 
classes em Marx, percebemos que a burguesia capitalista é movida pelo interesse econômico de acumulação de capital, enquanto o proletariado não tem interesse definido a não ser a sua própria sobrevivência, porque “[os] proletários nada têm a salvaguardar; sua missão é destruir todas as garantias e seguranças da propriedade privada até aqui existentes" 22 . Se mantivermos essa leitura certamente simplificada e mínima, podemos perceber os contornos que o proletariado está tomando no século XXI.

\section{O PRECARIADO E O DESAFIO NEOLIBERAL}

Nas primeiras páginas do seu livro O precariado - a nova classe perigosa, Guy Standing afirma que os grandes movimentos na história têm sido baseados nas (lutas de) classes ${ }^{23}$. O século XXI não é exceção. Porém, seguindo a própria dialética encarnada no desenvolvimento histórico, aquilo que o proletariado, como classe definida, deveria fazer - ou seja, uma revolução que conduzisse à abolição da propriedade privada, expressão da negação da humanidade intrínseca ao desenvolvimento do sistema de produção capitalista - não foi alcançado, e ainda não temos o comunismo previsto por Marx em nível global. Muito pelo contrário, as democracias liberais têm vindo a consolidar-se como modelo político ideal, quase hegemônico, baseando-se nos argumentos clássicos de que com democracia evitamos a tirania ou tipos de orientação política nacionalista; com democracia mantemos um sistema de direitos fundamentais; há uma expressa adesão ao valor de liberdade nas suas múltiplas facetas e instanciações, fazendo com que esta seja considerada em si mesma como valor, e não meramente instrumental; há igual adesão a procedimentos que visam chegar a resultados mais justos e amplamente aceites pelos cidadãos; promove-se um ambiente de paz e por fim, com democracia, os países alcançam mais prosperidade ${ }^{24}$.

Porém, essa última premissa de que a democracia é condição para prosperidade tem sido contestada. $\mathrm{O}$ fenômeno do neoliberalismo, adotado no seio de democracias ocidentais consolidadas (a começar por Estados Unidos e Grã-Bretanha), veio questionar a solidez, coerência e futuro do projeto democrático.

O neoliberalismo, tal como descrito por Harvey (2011a) veio responder a uma crise do capitalismo na década de 1970. Sem querer entrar no detalhe do debate sobre coerências e incoerências entre teoria do neoliberalismo e fenômeno da neoliberalização, percebemos que, à falta de opções ideológicas, o neoliberalismo se apresentou como solução para a crise da acumulação de capital. Ou seja, podemos dizer que o neoliberalismo veio contestar diretamente a teoria econômica política de Keynes e propor um cenário de desmaterialização monetá-
[22] Marx, 2005, p. 48.

[23] Essa afirmação lembra a afirmação de Marx no Manifesto comunista quando o autor afirma que "a história de toda a sociedade existente é a história das lutas de classes".

[24] Dahl, Robert. On political equality. Yale: Yale University Press, 2006, pp. 53-59. 
[25] Harvey, David. A Brief history of neoliberalism. Nova York: Oxford University Press, 2011a, p.38 ria, flexibilidade financeira e reestruturação de prioridades de políticas públicas em nome da salvação do sistema do capitalismo. O fato é que a cada onda de neoliberalização no mundo há uma concentração de riqueza em 0,01\% da população. Perguntamos, então: os ricos ficarem mais ricos, e os pobres ficarem mais pobres, é um acidente, ou, pelo contrário, reflete um projeto político específico queé de natureza antidemocrática, e, em última análise, antipolítica (no sentido aristotélico e arendtiano e não no sentido "comum", instrumental e profissional que o termo adquiriu nas últimas décadas)? Parece ser o último caso. Então, em que consiste essa estratégia e quais as suas implicações?

A estratégia neoliberal consiste na disciplinarização das forças de trabalho, na reestruturação da dívida pública dos países, na flexibilização do mercado de trabalho, na abertura dos mercados em nome da competitividade, na privatização de bens públicos, desregulamentação, na reinvenção permanente de formas de "acumulação primitiva" (ou acumulação por despossessão, como Harvey propõe), entre outras. Essas medidas permitem, em princípio, reduzir os custos de produção, melhorar a qualidade, aumentar a eficiência e produtividade, afetando diretamente o consumidor (Harvey, 2011a, p. 65). O atrativo do discurso neoliberal é facilmente identificável. Nascidos e criados num ambiente marcado por lutas de classe que cumpriram a crucial função de expansão de direitos de primeira, segunda e terceira geração, qualquer apelo ao reconhecimento da importância da liberdade individual, iniciativa e autonomia, se torna atraente. Porém, como Polanyi previu em 1944, há dois tipos de liberdade, uma boa e uma má. A boa liberdade conduz à liberdade de consciência, de expressão, de associação, de autodeterminação. Essa boa liberdade foi fruto, também, do sistema capitalista. Mas a liberdade má expressa-se como liberdade para explorar e oprimir o próximo, para acumular por motivos meramente individualistas e cortados de todo e qualquer sentido sociale de comunidade. O projeto neoliberal tem mostrado como a má liberdade tem ganhado progressivamente as batalhas, à custa de estratégias antidemocráticas e até mesmo autoritárias. Como Harvey bem diz,

Trinta anos de liberdades neoliberais, contudo, restauraram não só o poder de uma classe capitalista estreita e bem definida. Elas também produziram imensas concentrações de poder corporativo na energia, nos media, farmacêuticas, transportes, e até retalho (como o Wal-Mart). A liberdade do mercado que o Bush proclama como máximo ponto de aspiração humana nada maisé do que o meio conveniente para espalharo podercorporativo do monopólio e a Coca-Cola em todo lado, sem barreiras ${ }^{25}$.

Essa expansão dos mercados, que procurava recuperar os níveis de crescimento econômico na década de 1980, não cumpriu propria- 
mente a sua função. A neoliberalização tem gerado ou estagnação econômica, nos países sob intervenção do FMI, ou crescimento seguido de colapso (como foi o caso da Argentina). Hoje assistimos à multiplicação de crises que são endêmicas e contagiosas ${ }^{26}$, a última de $2007-$ 2008 , cujos efeitos ainda estão a ser tratados ou controlados, como é visível na crise da dívida pública de vários países europeus ${ }^{27}$.

Essa transformação levada a cabo pelo neoliberalismo trouxe uma reconfiguração das classes sociais, suas relações e sua consciência. $\mathrm{O}$ discurso e prática da flexibilização do trabalho levou a renegociações das condições do contrato de trabalho, resultando na perda de muitos dos direitos conquistados no séculoXX.Assim, o proletariado descrito por Marxé apenas uma pequena parcela da classe universal, o precariado, que não tem ainda consciência e existência para si. Diferentemente do proletariado, o precariado não se encaixa na divisão de classes sociais tradicionais; por um lado, não tem relações de confiança com o capital ou com o Estado, por outro lado, não tem contrato de trabalho típico do proletariado (que permite ganhar consciência de si enquanto pertença a uma "classe").

O precariado consiste em pessoas que não têm vários tipos de segurança relacionados com o trabalho: não têm segurança de emprego permanente, não têm proteção contra eventuais despedimentos; não têm oportunidades de ascensão de carreira; não têm geralmente proteção de trabalho como seguro de saúde ou de acidentes pessoais; não têm oportunidade de aperfeiçoamento na profissão; não têm garantia de um rendimento estável; e, por fim, não têm uma voz coletiva no mercado de trabalho ${ }^{28}$. Todas essas ausências são graves porque definem o que o precariado vai ser, pela negatividade. O precariado abarca um conjunto diversificado de pessoas, vários tipos de profissão, de formação acadêmica, de background cultural e socioeconômico, mas é uma classe (ainda em formação) que, à semelhança do proletariado de Marx, representa a alienação da humanidade. Standing diz que "o precariado não existe por si mesmo. É também definido por aquilo que não é" 29.

Quem faz parte do precariado? Pelas estimativas de Standing, um quarto da população mundial adulta. Ele diz que

[i]sto não é só uma questão de ter emprego inseguro, de estar em empregos por duração limitada e com proteção laboral mínima, embora isto seja comum. [Estar no precariado é] estar num estatuto que não oferece sentido de carreira, sentido de identidade ocupacional segura e poucos, se é que existem, têm beneficios do estado ou da empresajo.

Qualquer um de nós pode "cair" no precariado. O precariado cobre virtualmente todos nós. Os mais jovens são claramente os mais
[26] Harvey, 2011 (a), p.94

[27] Harvey, David. The enigma of capital and the crises of capitalism. Londres: Profile Books, 2011 (b).

[28] Standing, Guy. The precariat the new dangerous class. Nova York: Bloomsbury Academic, 2011, p.10

[29] Standing, 2011, p.23

[30] Standing, 2011, p.24 
[31] Harvey, 2011b, p.15

[32] Harvey, 2011b, p.61

[33] Standing, 2011, p.25

[34] Standing, 2011, p.117

[35] Standing, 2011, p.155 vulneráveis, porque não conseguem entrar na grande máquina da mercantilização generalizada, mas também se identificam todos os salariados que vivem apenas do seu salário, e que portanto ficam à mercê da mudança das regras do jogo do capital; inclui igualmente os tradicionalmente excluídos, i.e., os criminalizados, e assiste-se ainda a uma feminização do mercado (que traz consigo a feminização da pobreza em escala mundial) ${ }^{31}$.

Num contexto em que todos pertencemos, potencial ou atualmente, ao precariado, qualquer reconfiguração de luta de classes no sentido tradicional de Marx se torna um desafio. Não temos aqui esperança de construir uma imagem de classe relativamente homogênea, quer pela sua formação, quer pela sua profissão, quer pela sua experiência ou pertença a um grupo, até porque a estratégia do capitalismo sob os auspícios neoliberaiséjogar com as diferenças étnicas, raciais, linguísticas, políticas e religiosas, para lucrar com a "guerra de todos contra todos" no mercado de trabalho ${ }^{32}$. O grande problema é exatamente este:o precariado ainda não é uma classe-para-si "porque está em guerra consigo mesmo" 33 , e isso se deve ao fato de que minorias dentro dessa grande maioria se atacam entre si, recusandover que a causa para a partilha da mesma realidadeé também ela comum.

O que essa não classe confirma éque Marx estava certo - enquanto o modo de produção capitalista persistir, agora governado por tentáculos imperialistas neoliberais numa escala global na qual estamos todos "ligados", "[o trabalho] degrada e desvaloriza algumas das mais necessárias e valiosas atividades - a reprodução das nossas próprias capacidades assim como as das gerações futuras e atividades que preservam a nossa existência social" 34 . Standing acredita que, apesar da constelação atual, o precariado está progressivamente a formar-se enquanto classe, "capaz de identificar aquilo que deseja combater e o que deseja construir" 35 . O que fazer?

Idealmente, seria preciso recuperaro sentido de trabalho enquanto atividade criativa, não alienada. A ideia de Marx era exatamente esta: uma vez que a sociedade tenha sido capaz de produzir o essencial para a satisfação das suas necessidades materiais, deveríamos desenvolver as nossas capacidades e talentos. Mas isso implica a existência de algum tipo de garantia e segurança no nível do domínio da necessidade, para que os indivíduos consigam não só libertar-se, mas ser livres.

Standing oferece algumas alternativas: a redefinição de um discurso reivindicativo por direitos laborais, com salários justos, com transparência de política de contratação, com respeito por um código ético. Também defende a ideia de que temos de recuperar um sentido positivo (que pode ser interpretado como republicano) de liberdade em que ser livre implica agir em conjunto, participar na comunidade, partilhar e construir um projeto comum. Ou seja, devemos pôr de lado a versão 
neoliberal de liberdade que nos diz que somos livres para competir, para consumir e para trabalhar, mas que terminamos como escravos do sistema. Porém, a maioria das suas propostas está assente numa normatividade que escapa ao imperativo da práxis marxista.Aquestão central torna-se: como convencer, persuadir e levar os detentores dos meios de produção em escala global a respeitar a dignidade do outro, a ver o outro como pessoa e não como mercadoria? A resposta foi bem dada por Harvey quando diz que "[a] primeira lição que devemos aprender é que um capitalismo ético, não explorador e socialmente justo que se traduz no benefício de todos é impossível. Contradiz a natureza do próprio capital" 36 . Além disso, "as classes governantes raramente, seé que alguma vez, voluntariamente abdicam do seu poder" 37.

Querentendamos o neoliberalismo como percurso errado tomado pelo capitalismo, quer como estratégia de restauração do poder das elites (mesmo se estas mudam), parece-me que Harvey está correto ao nos alertar de que, também nós, somos moldados pela ideologia neoliberal. Não adianta simplesmente propor um modelo alternativo, baseado em solidariedade, espírito de comunidade, igualdade política, ou apelar à importância vital de o ser humano ter um espaço de privacidade onde possa escolher de forma autônoma e livre. Como convencer um neoliberal de que a solidariedade é importante, se ele é advogado incansável do individualismo feroz? Mesmo as propostas que se têm vindo a implementar no Brasil, com a Bolsa Família (que Standing, entre outros defenderia em escala global), não são capazes, por si só, de reverter o percurso neoliberal.

Se o precariado ainda se está a constituir como classe, e se guarda a esperança de universalidade dentro de si,é preciso recuperar todas essas premissas que têm no seu núcleo duro a concepção do ser humano enquanto ser social; mas essa recuperação tem de ser feita na prática, na associação real entre indivíduos, para que estes possam inventar meios de mobilização e criar uma lista de reivindicações positivas. A crítica e a dialética cumprem, nesta fase, uma função inigualável.

Essa crítica tem de começar pela exposição das condições concretas da nossa vida, percebendo que essas condições são determinadas por um princípio motor de acumulação de capital que dialeticamente se reinventa no tempo desde a instauração do sistema capitalista. Essa foi, afinal, uma das razões pelas quais Marx escreveu $O$ capital. A acumulação de capital é "multiplicação do proletariado" 38 , ou seja, a acumulação de capital implica o reordenamento da divisão social do trabalho, implica a expansão dessa divisão, implica uma expropriação contínua dos indivíduos em face de seus meios de produção, sejam estes quais forem, criando novos espaços a ser preenchidos, novas necessidades que têm de ser colmatadas, nova sequência expansiva do mercado. Com isso em mente, percebemos também como Marx per-

[36] Harvey, 2011b, p.239

[37] Harvey, 2011b, p.153 
[39] Marx em Perelman, Michael. The invention of capitalism. Londres: Duke University Press, 2000, p. 31

[4o] Harvey, 2011b, p.26o manece atual. A crueldade denunciada por ele no fenômeno de "acumulação primitiva” perpetua-se até os dias de hoje. Como o autor diz,

não é suficiente que as condições do trabalho sejam concentradas num polo da sociedade na forma de capital, e que no outro polo encontremos as massas de homens agrupados que não têm nada a vender a não ser o seu poder de trabalho. Nem é suficiente que eles sejam compelidos a vender-se voluntariamente. O avanço da produção capitalista desenvolve uma classe trabalhadora que, pela educação, tradição e hábito, olha para os requisitos desse modo de produção como leis naturais autoevidentes. A organização do processo de produção capitalista, uma vez totalmente desenvolvido, quebra qualquer tipo de resistência. A constante geração de uma relativa população extra mantém as leis da oferta e da procura do trabalho, e portanto os salários, dentro de limites estreitos que correspondem aos requisitos da valorização do capital. A compulsão silenciosa das relações econômicas põe o selo na dominação do capitalista sobre o trabalhador. [...] a burguesia emergente precisa do poder do Estado e usa-o para regular os salários, i.e., para forçá- los dentro dos limites que permitam fazerum lucro, alargaro dia de trabalho e mantero trabalhadorem um nivel normal de dependência. Esteéum aspecto essencial da chamada acumulação primitiva39.

Marx estava bem consciente de que à acumulação primitiva se seguiriam novas formas de dirigir o mercado, o que implicava expropriar os indivíduos de tudo o que ainda lhes restasse. Essa lógica, porém, estender-se-ia aos próprios capitalistas, de forma de que a tendência natural seria que os pequenos e médios capitalistas fossem progressivamente absorvidos pelos maiores. Ou seja, a expropriação que está na base do modo de produção capitalista, levada à sua completude, só pode conduzir à expropriação de todos os indivíduos e a um monopólio sem espaço para competição. Lógica e dialeticamente, o capitalismo do século XXI parece estar a abrir portas para uma reconfiguração total do sistema.

Mas essa reconfiguração não virá de forma pacífica, nem será suave. Se "a acumulação do capital nunca para [e] tem de ser parada", se "a classe capitalista nunca abdicará do seu poder [e] terá de ser expropriada" ${ }^{\circ}$, é preciso aprender com os erros do passado - a má experiência do socialismo soviético e as consequências devastadoras do sistema capitalista - e articular um movimento social e político capaz de transcender as diferenças específicas dos indivíduos e suas nações, e uni-los em prol de um objetivo comum: a existência para lá da mera cruel sobrevivência. Afinal, a emancipação humana é ainda possível, pois ainda está por realizar. 
Dahl, Robert. On political equality. Yale: Yale University Press, 2006. Eagleton, Terry. Why Marx was right. Yale: Yale University Press, 2011. Harvey, David. A brief history of neoliberalism. Nova York: Oxford University Press, 2011 .

. The enigma of capital and the crises of capitalism. Londres:

Profile Books, 2o11b.

Hegel, G.H.F.Elements of the philosophy of right. Tradução de H.B. Nisbet. Cambridge: Cambridge University Press, 2003.

Marcuse, Herbert. Reason and revolution-Hegel and the rise of social theory. Boston: Beacon Press, 1978.

Marx, Karl.In:Tucker (org.).The Marx-Engels Reader. Nova York:W.W. Norton \& Company, 1978.

. Manifesto comunista. Tradução Álvaro Pina. São Paulo:

Boitempo Editorial, 2005.

- Para a crítica da filosofia do direito de Hegel. Tradução de Artur Morão. Covilhã:Textos Clássicos LusoSofia, 2008.

Perelman, Michael. The invention of capitalism. Londres: Duke University Press, 2000.

Singer, Peter. Marx - a very short introduction. Nova York: Oxford University Press, 2000.

Standing, Guy. The precariat - the new dangerous class. Nova York: Bloomsbury Academic, 2011.

Taylor, Charles. Hegel. Cambridge: Cambridge University Press, 1999. Wood, Allen W. Hegel's ethical thought. Cambridge: Cambridge University Press, 1990.

Recebido para publicaçao em 8 de

janeiro de 2015.

NOVOS ESTUDOS

CEBRAP

101, março 2015

pp. 97-114

MARTA NunES DA Costaé professora visitante no Departamento de Filosofia da Universidade Federal de Santa Catarina. É doutorada em Ciência Política pela New School for Social Research e autora de Modelos Democráticos (Belo Horizonte: Arraes Editora, 2013). 